Journal of Social Sciences (COES\&RJ-JSS)

ISSN (E): 2305-9249 ISSN (P): 2305-9494

Publisher: Centre of Excellence for Scientific \& Research Journalism, COES\&RJ LLC

Online Publication Date: $1^{\text {st }}$ October 2017

Online Issue: Volume 6, Number 4, October 2017

DOI: $10.25255 /$ jss.2017.6.4.802.815

\title{
Analyzing Factors Affect on Five Stars Occupational Safety in Aqaba Special Economic Zone Authority (ASEZA)
}

\author{
Dr. Omar A Jawabreh \\ Department of Hotel Management, Faculty of Tourism and Hospitality, \\ The University of Jordan
}

\section{Article History:}

Received Date: $14^{\text {th }}$ September 2016; Revised Date: $14^{\text {th }}$ October 2016; Acceptance Date: $12^{\text {th }}$ November 2016; Publication Date: 1st October 2017

\begin{abstract}
:
This study aims to analyze factors affect on five stars occupational safety in Aqaba Special Economic Zone Authority (ASEZA). A questionnaire and personal interviews are used to collect data. A group of (153) questionnaire is collected back out of (166) and (13) questionnaire is excluded, so results of the study depends on (142) employers. The results of study indicate that training can be the most effective factor that may has a key role on employs' safety in hotels. Employers should start their safety training courses as soon as they enroll to work. More research should be conducted to find more effective factors that related to work accidents.
\end{abstract}

\section{Key words:}

Aqaba, ASEZA, occupational safety', Occupational Safety and Security Program, Kitchen design in hotels, Safety of kitchen workers.

\section{Citation:}

Jawabreh, Dr. Omar A. (2017); Analyzing Factors Affect on Five Stars Occupational Safety in Aqaba Special Economic Zone Authority (ASEZA); Journal of Social Sciences (COES\&RJ-JSS), Vol.6,No.4,pp:802-815; DOI: 10.25255/jss.2017.6.4.802.815. 
تحليل بعض العوامل المؤثرة على سلامة موظفي فنادق الخمس نجوم في منطقة العقبة

الاقتصادية الخاصة (ASEZA)

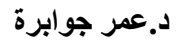

أستاذ مساعد-قسم ادارة الفنادق ـ كلية السياحة و الفندقة ـالجامعة الأردنية ـ الأردن

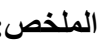

تهدف الدراسة الى تحليل بعض العو امل المؤثرة على سلامة موظفي فنادق الخمس نجوم في منطقة العقبة الاقتصادية

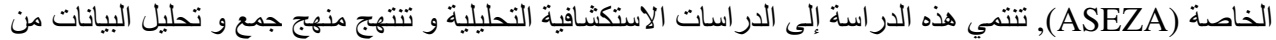

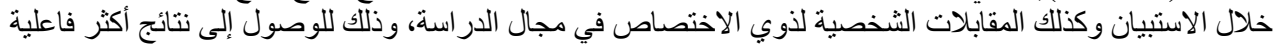

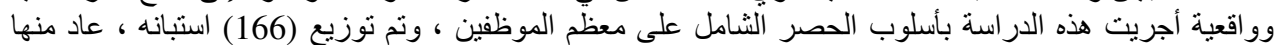

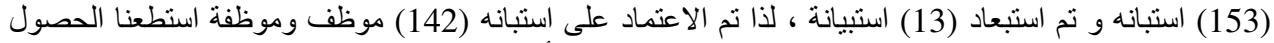

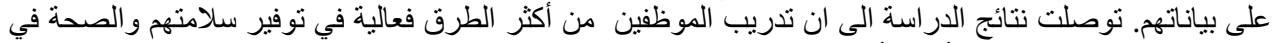

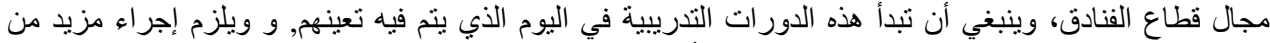

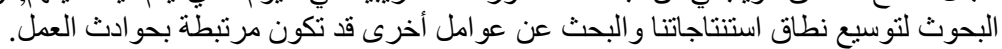

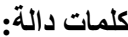
السلامة المهنية, العقبة, برنامج الأمن و السلامة المهنية, تصميم المطبخ في الفنادق, سلامة العاملين في المطبخ.

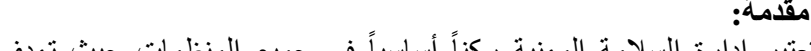

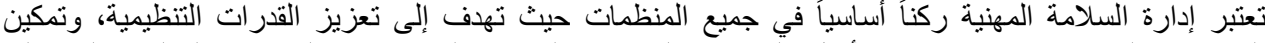

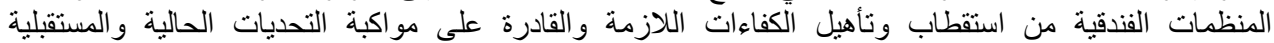

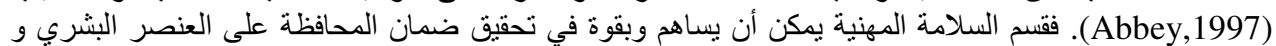

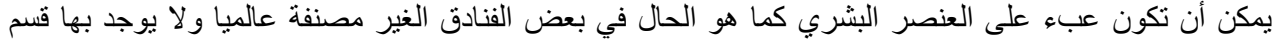

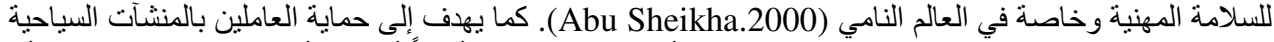

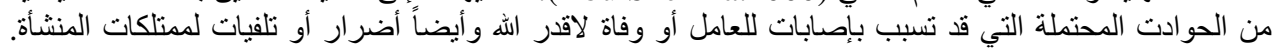

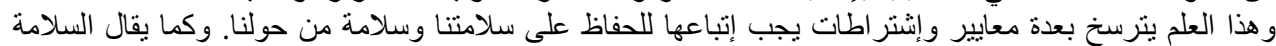

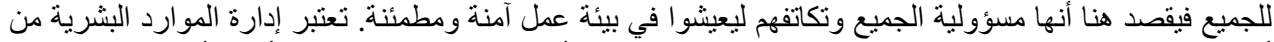

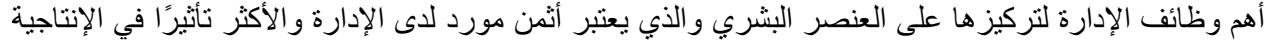

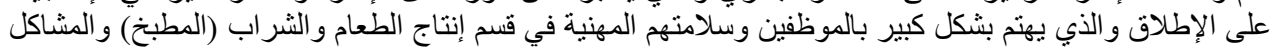

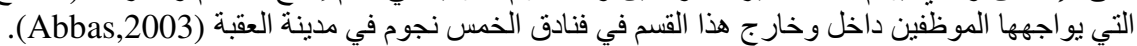

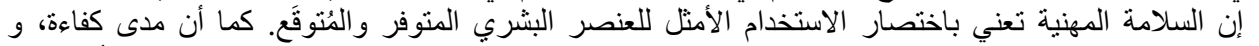

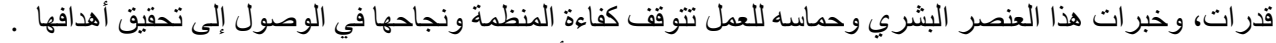
(Al-Mari,1987 Ábu Saud,1989; Qahaf,1988)

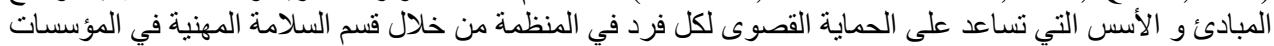

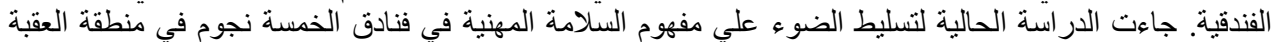

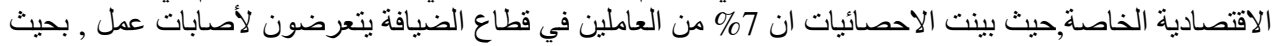

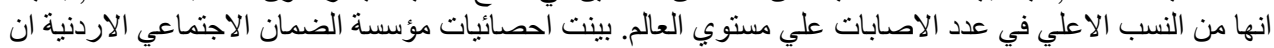

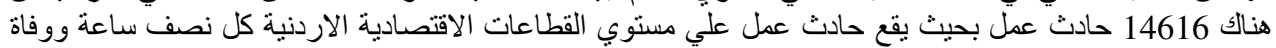

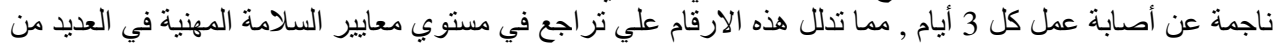

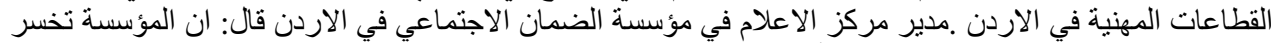

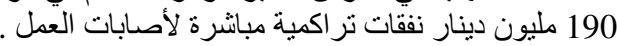

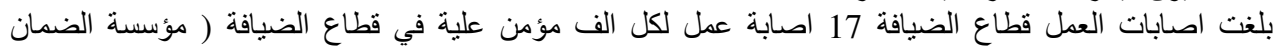

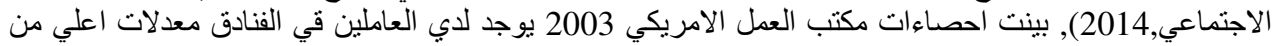

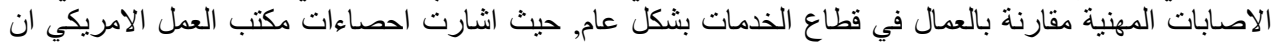

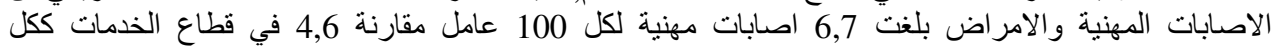

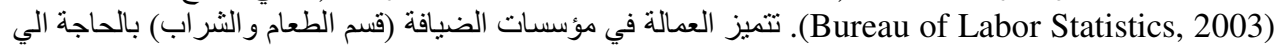

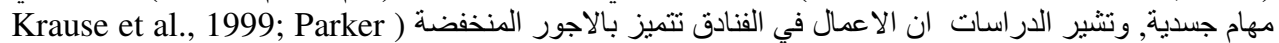
الي وجود ادلة دامغة ان (and Krause, 1999; AFL-CIO Working,2002; Bernhardt et al., 2003,

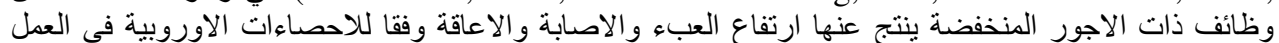
فقد وقعت 190736 حوادث مهنية اسفرت عن غياب اكثر من ثلاثة ايام من العمل, فئر 


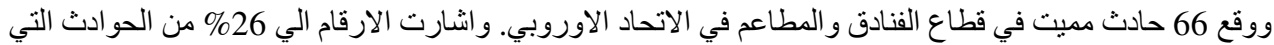

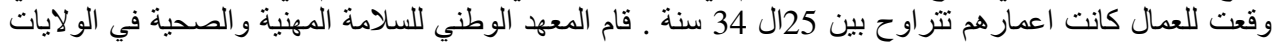

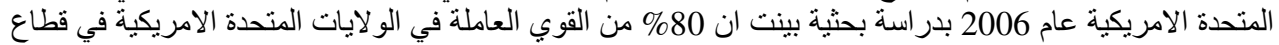

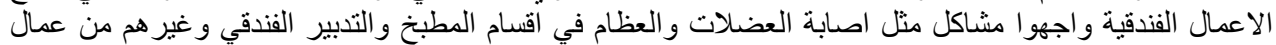

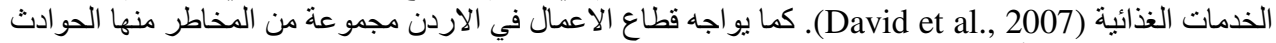

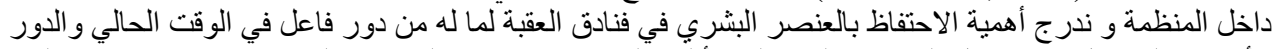

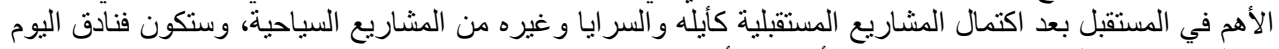

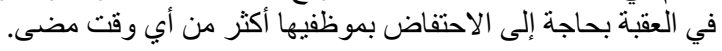
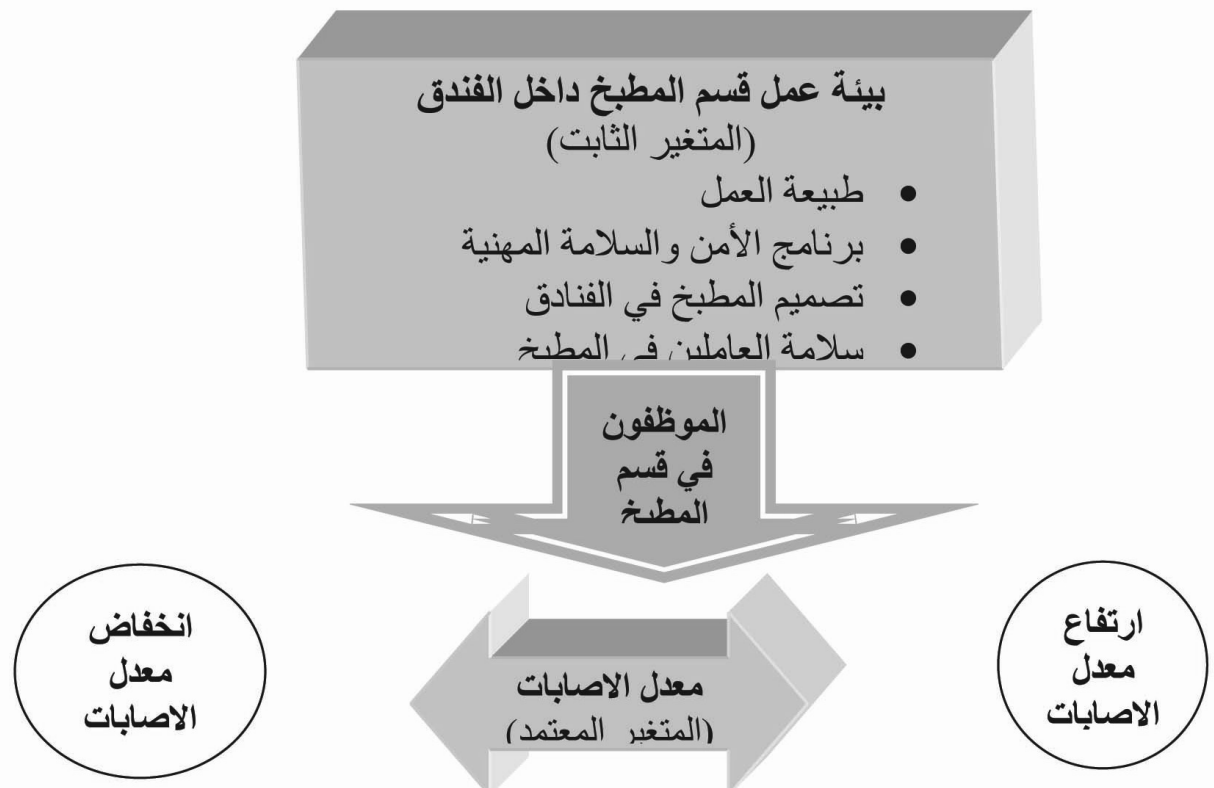

شكل رقم (1) نموذج الدراسة

أولا: الدراسات السابقة

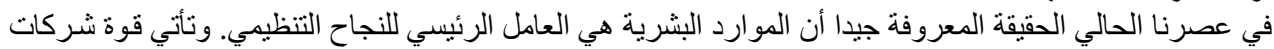

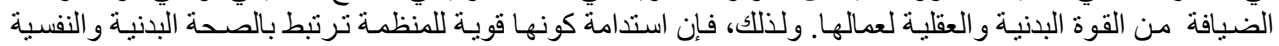

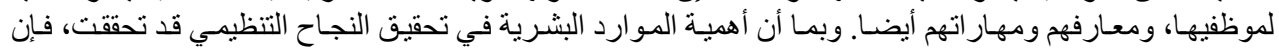

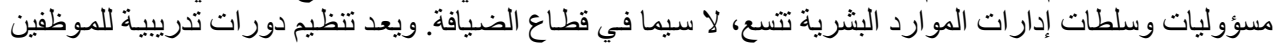

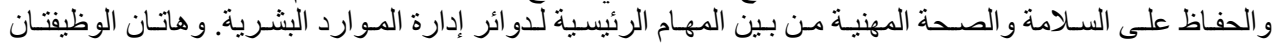

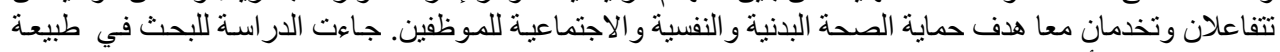

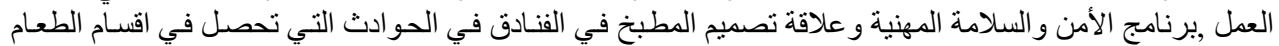

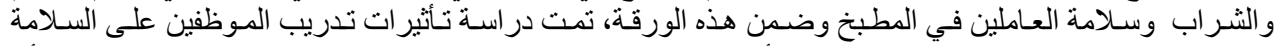

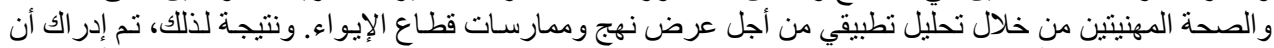

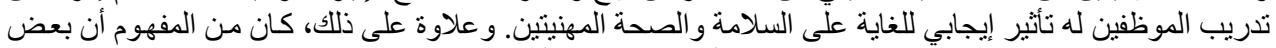

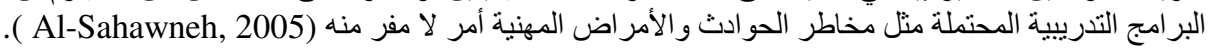

تتميز العمالة في مؤسسات الضيافة (قسم الطعام و الثر اب) بالحاجة الي مهام جسدية, وتشير الدراسات ان الاعمال في ;

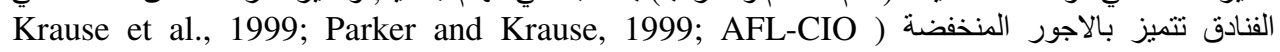
(Working for America Institute, 2002; Bernhardt et al., 2003, Tawfiq,2006; Sarhan, ) الاجور المنخفضة ينتج عنها ارتفاع العبء والاصنابة والاعاقة. ذكر تقرير قطاع الفنادق الفات 


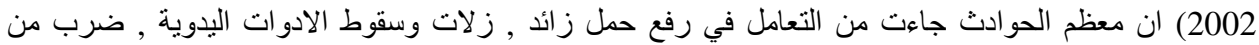

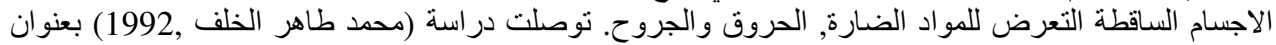

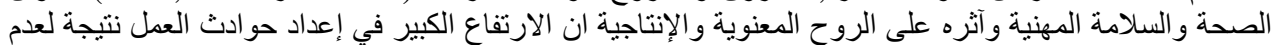

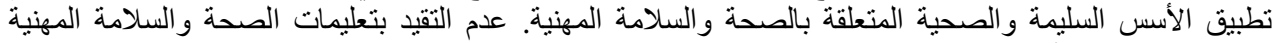

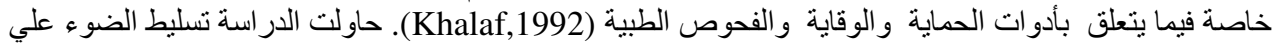

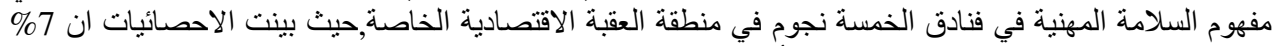

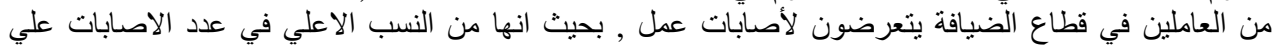

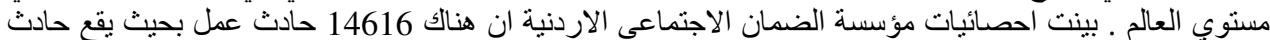

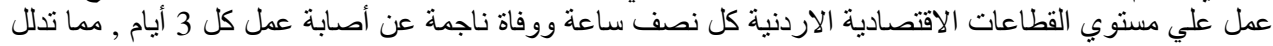

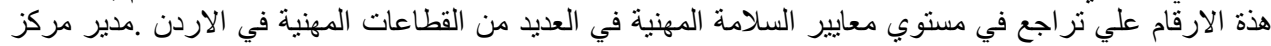

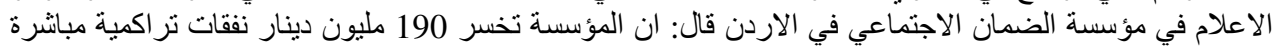

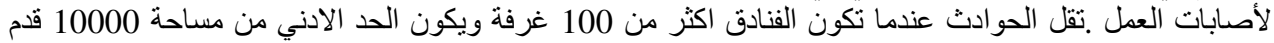

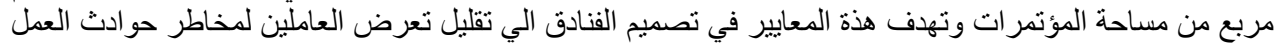

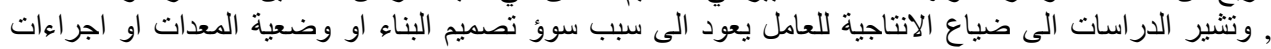

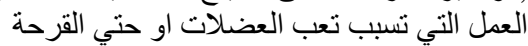

(Mohammed et al , 2014; Dasinger et al., 1999 ;

Pransky et al., 1999 ; Rosenman et al., 2000, Scherzer et al., 2005; Evanoff et al., 2002

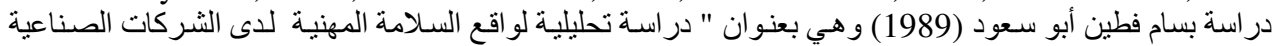

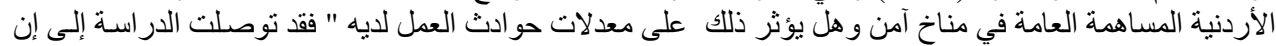

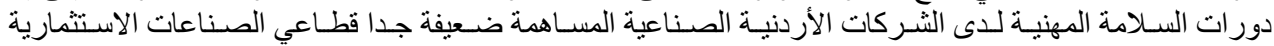

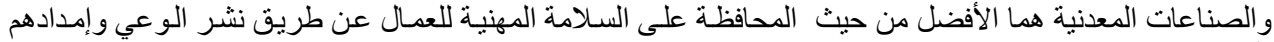

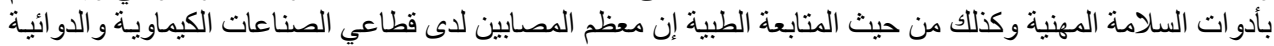

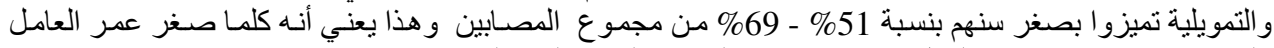

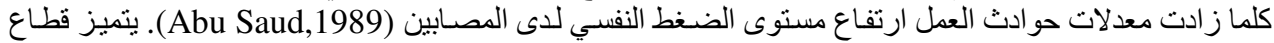

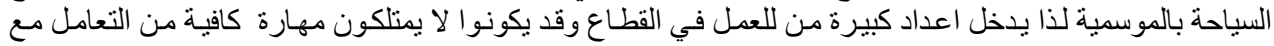

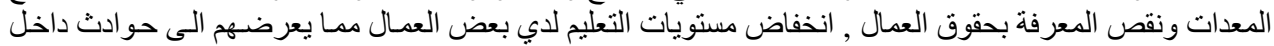

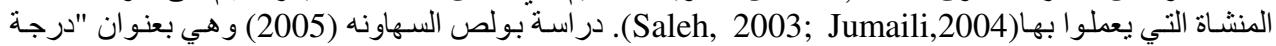

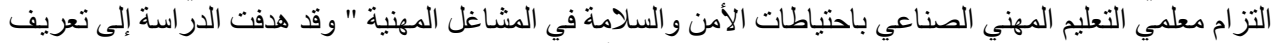

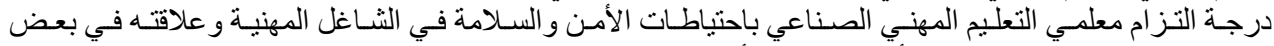

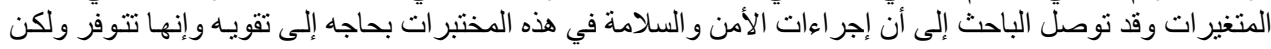
ليست إلى الحد الكافي (Al-Sahawneh,2005;Zidan,1995 ).

مشكلة الاراسة تسعى هذه الدراسة للتعرف على و اقع حال السلامة المهنية لموظفي قسم الإنتاج ( المطبخ) أحد أهم أقسام الطعام

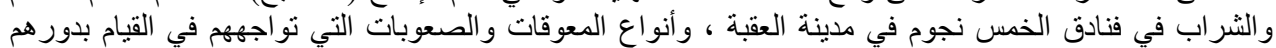
الخدمي المنشود، وما يترنب عليها من أثنار على أدائهم المهني.

أهداف الاراسة

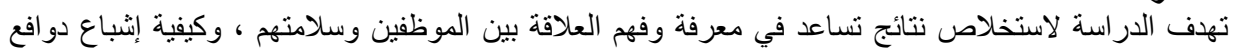

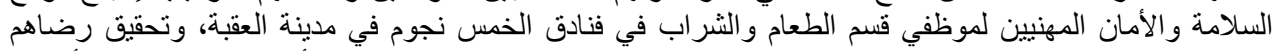

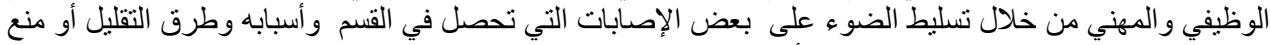

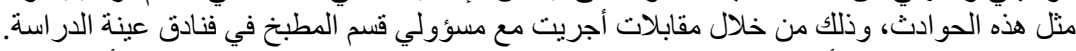

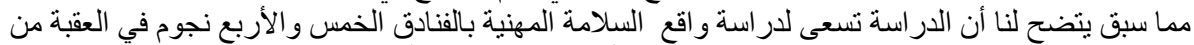

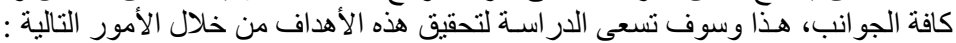

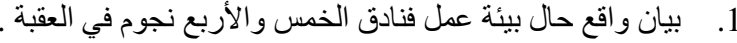
2.

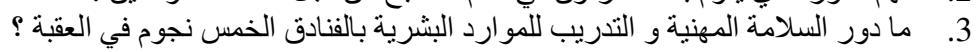
4. ما واقع السلامة المهنية بالفنادق الخمس نجوم في مدينة العقبة ؟ 


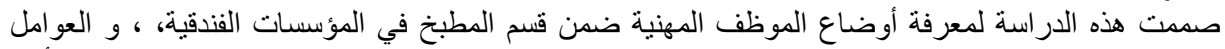

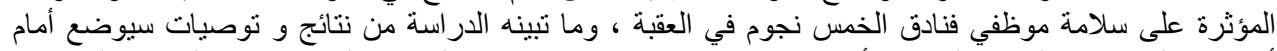

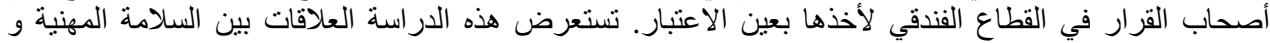

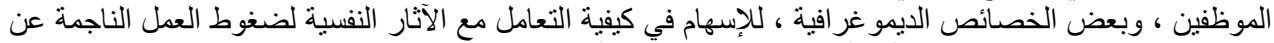

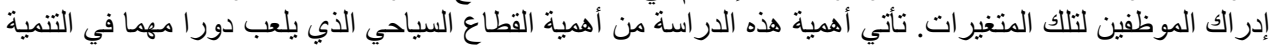

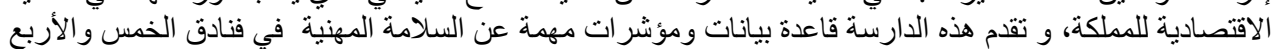

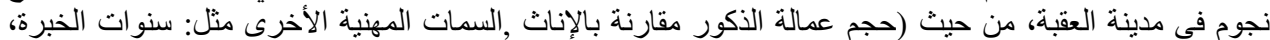
التأهيل والتدريب وقدرة الاستفادة منه، السلامة المهنية لهم في ظل الأوضاع المكات المهنية التي يعيشونها).

فرضيات الدراسة الزية الفرضية الرئيسية الأولى: لا ثوجد علاقة ذات دلالة إحصائية بين بيئة العمل في مطابخ فنادق الخمس نجوم في مدينة

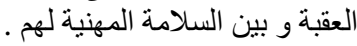

الفرضيات الفرعية للفرضية الرئيسية الأولى:

1- لا توجد علاقة ذات دلالة إحصائية بين طبيعة عمل الموظف في المطبخ في فنادق الخمس نجوم في مدينة العقبة

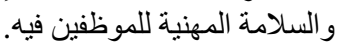
2- لا توجد علاقة ذات دلالة إحصائية بين برنامج الأمن و السلامة المهنية المنامة الموجود في قسم المطبخ لفنادق الخمس

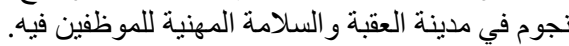

3- لا توجد علاقة ذات دلالة إحصائية بين قسم السلامة المهنية في فنادق الخمس نجوم في مدينة العقبة والسلامة المهنية للموظفين فيه.

4- لا نوجد علاقة ذات دلالة إحصائية بين تصميم المطبخ في فنادق الخمس نجوم في مدينة العقبة و السلامة المهنية لالموظفين فيه. الفرضية الرئيسية الثانية: لانية نوجد علاقة ذات دلالة إحصائية بين العو امل الديمو غر افية للموظفين و بين سلامتهم

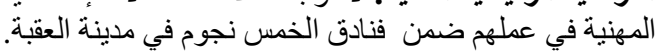

تساؤلات الدراسة

بما أن هذه الدر اسة تعد من الدر اسات الاستكثافية التحليلية، و أنها الأولى من نو عها في المجتمع المحلي لمنطقة

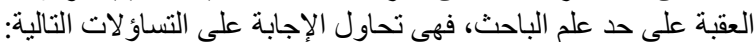

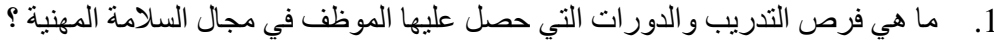

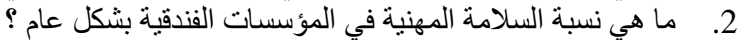

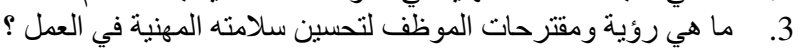

ثانياً: اختبار صدق استمارة الاستبيان

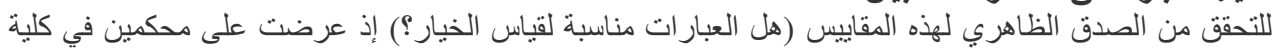
العقبة الجامعية، وقد اخذ الباحثون بالكثير مما أبدوه من ملاحظات قيمة بشأن الحذف وات والتعديل و إعادة الصياغة.

ثالثاً: الأساليب الإحصائية و هي على نو عين:

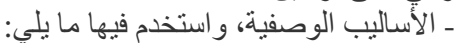

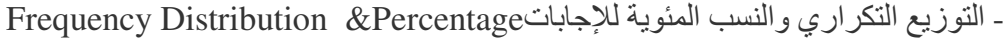

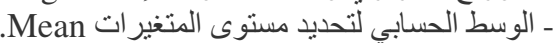

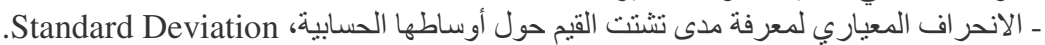

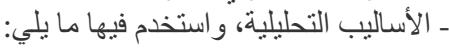

الانحدار الخطي البسيط (Simple Linear Regression) لقياس تأثير متغير في متغير أخر.

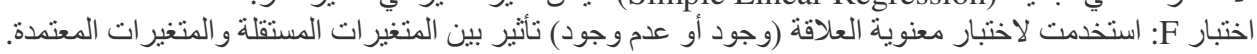


L : لمعرفة درجة مساهمة المتغير المستقل في المتغير المعتمد.

رابعاً: محددات وصعوبات الاراسة

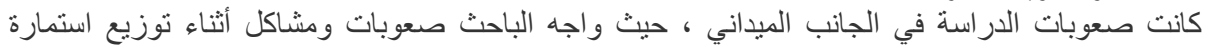

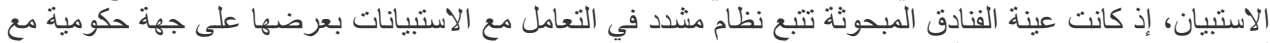

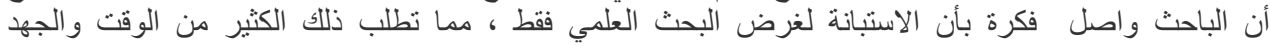

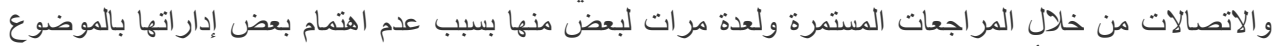

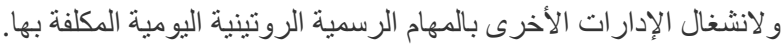

تنتمي هذه الدراسة إلى الدراسات الاستكثافية التحليلية و تتنهج منهج جمع و تحليل البيانات من خلال الاستبيان

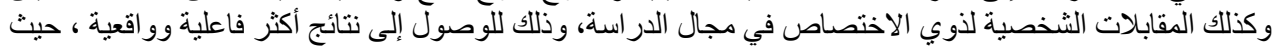

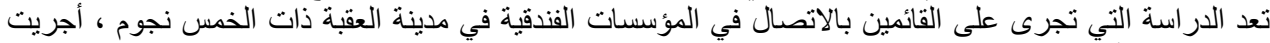

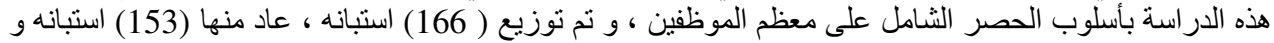

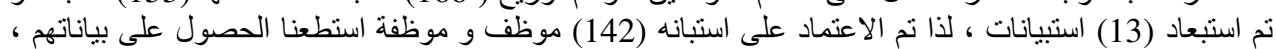
ويعملون في المؤسسات الفندقية الأردنية ذات الخمس و والأربع نجوم في مدينة العقبة ، جمعت البيانات منهم عن طريق الاستبيان، ويمثلون مجتمع البحث و عينة الدارسة .

المقابلات الميدانية

قام الباحث بمقابلات شخصية مع بعض العاملين في فنادق عينة الدراسة من موظفي قسم إنتاج الطعام و الثر اب (القابل

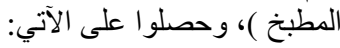

المقابلة الأولى: فندق كمبنسكي / العقبة

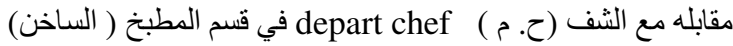

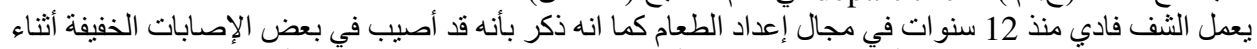

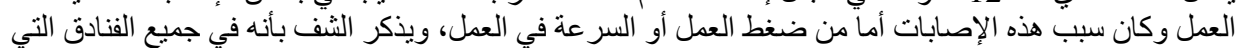

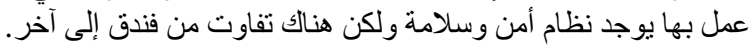

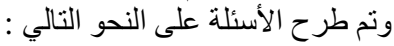

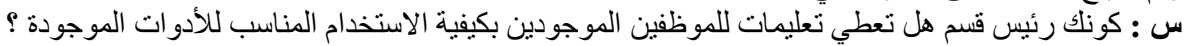

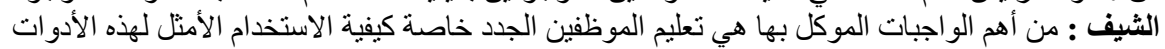

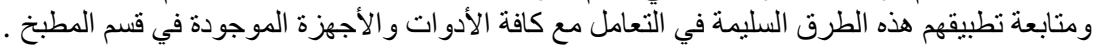

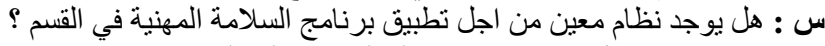

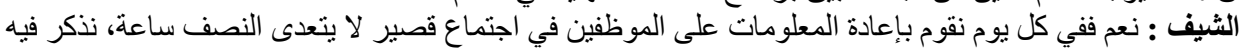

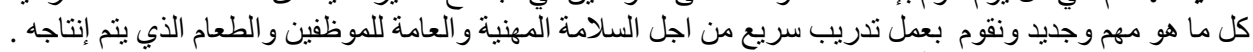

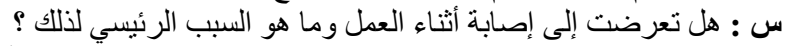

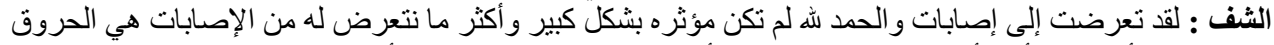

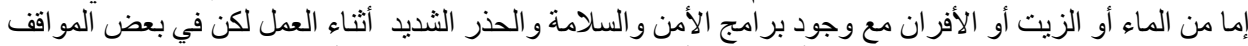

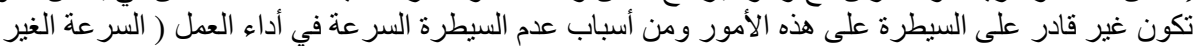
مطلوبة)

وضغط العمل ( عندما يطلب منك القيام بعدة أمور في وقت واحد فهذا يؤدي إلى تشتيت الأفكار وقلة السيطرة) .

المقابلة الثانية: فندق رادسون بلو / العقبة

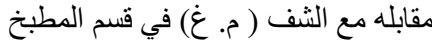

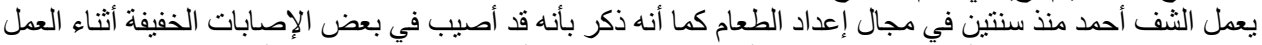

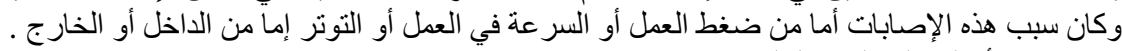

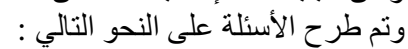

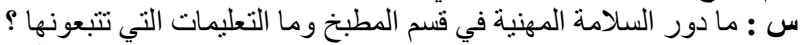

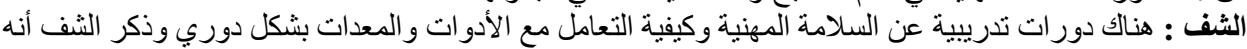
بالنسبة للتعامل مع الأدوات ور المعدات من ناحية السلامة المهنية فهي كالآتي : 


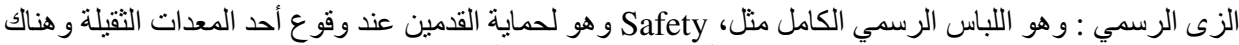

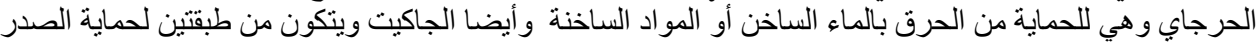

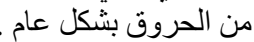
الأدو ات و المعدات : إذا وجد في أله أحد المعدات خلل ما مثل آلة تقطيع اللحوم أو سماع صوت غريب يتم إبلاغ الصيانة

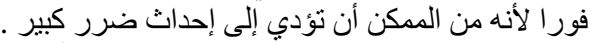

• : و هي النظافة الثخصية ( الثعر ، الأظافر، و الجسم كاملا ) وبالتشديد على غسل الأيدي باستمر ار ممكن أن تكون كل 15 دقيقة :

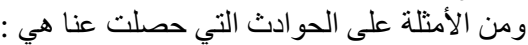

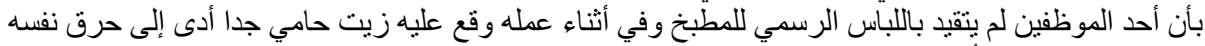
حروق شديدة وذللك لأنه لم يتقيد بالتعليمات نحو اللباس وسلامته المهنية للمنية في العمل .

المعالجة الإحصائية

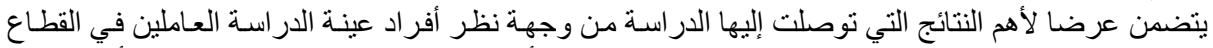

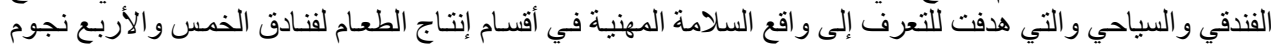
في مدينة العقبة، وقد اعتمد المعيار التالي للحكم على المنتوسطات الحسابية وهو :

1: 1.00 - 1.49 يقابل التقدير بدرجة منخفضة جدا

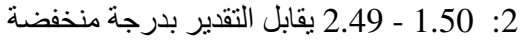

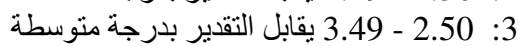
4 5: 4.50 - 5.00 يقابل التقدير بدرجة كبيرة جدا

\section{وفيما يلي عرضا للنتائج وفقا لأسئلة الدراسة}

ـ ما واقع السلامة المهنية في أقسام إنتاج الطعام لفنادق الخمس و الأربع نجوم في مدينـة العقبة من وجهة نظر العاملين

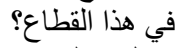

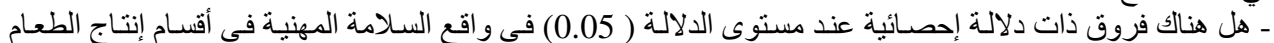

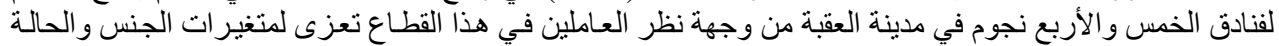

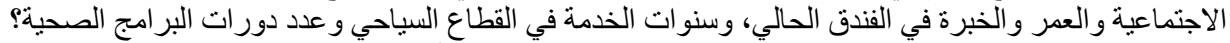

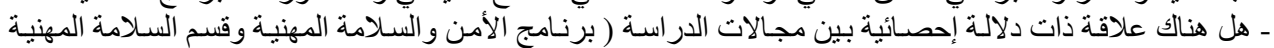

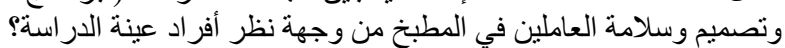

جدول رقم 1. المتوسطات الحسابية والانحر افات المعيارية لتقديرات أفراد العينة لواقع برنامج الأمن والسلامة

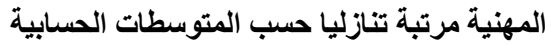

\begin{tabular}{|c|c|c|c|c|}
\hline 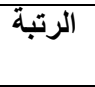 & الانحراف & المتوسط الحسابي & الفقرات & 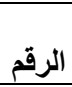 \\
\hline 2 & .61 & 4.58 & 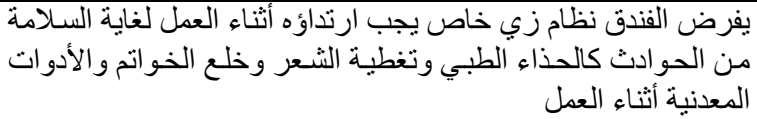 & 2 \\
\hline 1 & .64 & 4.58 & 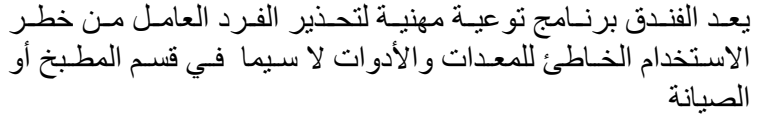 & 1 \\
\hline 3 & .68 & 4.55 & هناللك توجيهات بضرورة عدم العبث أو اللعب بالمعدات أو الأدوات & 3 \\
\hline 4 & .73 & 4.54 & 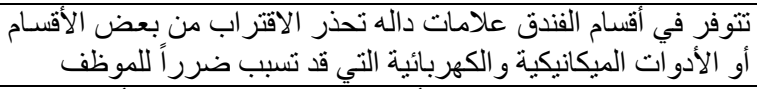 & 4 \\
\hline 5 & .84 & 4.52 & يتوفر في الفندق عيادة طبيب و أدوية ومستلزمات إسعافات أولية & 6 \\
\hline 6 & 0.91 & 4.47 & أثثاء الكو ارث و الفندق على إعداد بر امج توعية أمنية خاصة بعمليات الإخلاء & 5 \\
\hline
\end{tabular}




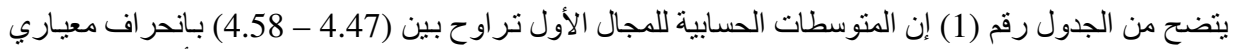

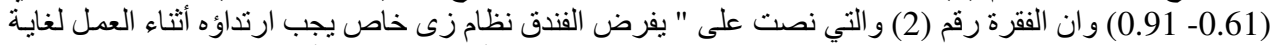

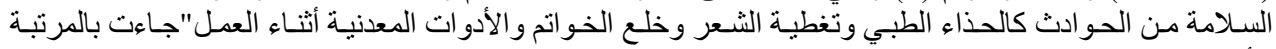

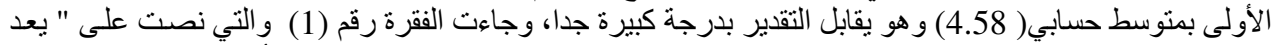

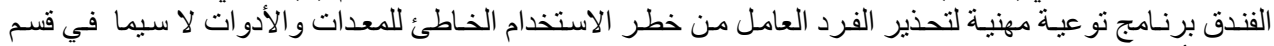

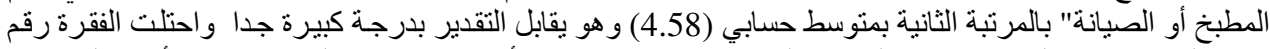

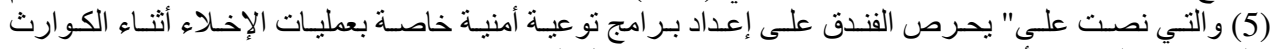

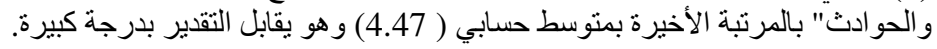

جدول رقم (2) المتوسطات الحسابية والانحرافات المعيارية لتقديرات أفراد العينة لواقع قسم السلامة المهنية مرتبة تنازليا حسب المتوسطات الحسابية

\begin{tabular}{|c|c|c|c|c|}
\hline 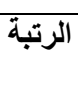 & 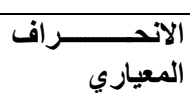 & 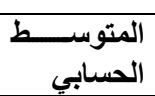 & الفقرات & 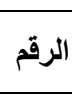 \\
\hline 1 & .83 & 4.35 & يوجد في الفندق قسم خاص يهتم بالسلامة المهنية & 7 \\
\hline 2 & .86 & 4.33 & هنالك دورات تدريبيه باستمر ار تؤكد على السلامة المهنية & 10 \\
\hline 3 & .84 & 4.31 & يقوم المشرف بإجر اء جو لات تفقديه لمتطلبات السلامة الفندقية & 9 \\
\hline 4 & .81 & 4.30 & توزع مهام السلامة المهنية على جميع أقسام الفندق & 8 \\
\hline 5 & .96 & 4.18 & و الستحامة الفندق بتوفير مدربين ذوي خبر ات فاعلـة لإدارة البر امج التدرييية & 11 \\
\hline 6 & 1.00 & 4.18 & يوفر الفندق كل ما هو جديد من بر امج ومعدات من اجل السلامة العامة & 12 \\
\hline
\end{tabular}

يتضح من الجدول رقم (2) إن المتوسطات الحسابية للمجال الثاني تراوح بين (4.18- (4.

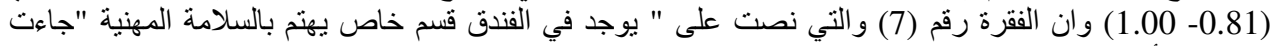

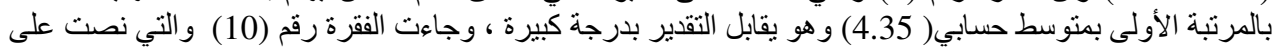

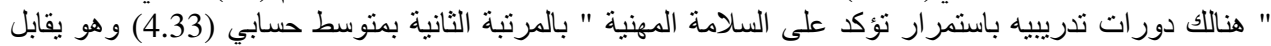

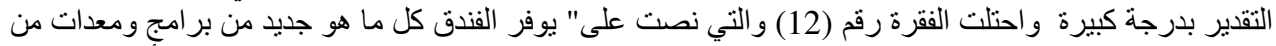

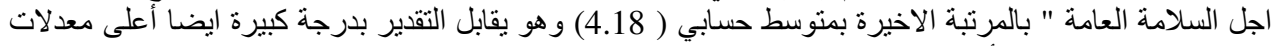

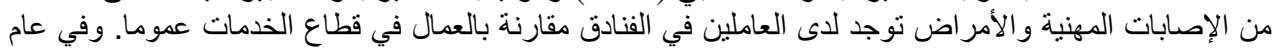

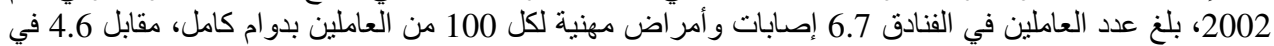

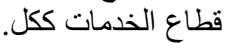

جدول رقم (3) المتوسطات الحسابية والانحر افات المعيارية لتقديرات افراد العينة لواقع تصميم المطبخ مرتبة تنازليا حسب المتوسطات الحسابية

\begin{tabular}{|c|c|c|c|c|}
\hline الرتبة & 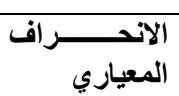 & 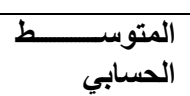 & الفقرات & 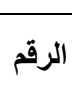 \\
\hline 1 & .56 & 4.68 & مساحة المطبخ واسعة وتوفر حرية الحركة للعاملين في المطبخ & 13 \\
\hline 2 & .57 & 4.67 & وجود عدد كافي من المغاسل لكثرة استخدامها & 20 \\
\hline 3 & .65 & 4.65 & تتوفر مخار ج للّطو ارئ في حالة حدوث مشكلة ما & 23 \\
\hline 4 & .55 & 4.57 & ومناسع المطبخ قريب من المطعم بحيث يتم تقديم الطعام بشكل سريع & 14 \\
\hline 5 & .69 & 4.55 & يتوفر في المطبخ مر اوح شفط لسحب البخار من المطبخ & 15 \\
\hline 6 & .74 & 4.55 & تتو افر الإضـاءة الجيدة و المناسبة للعاملين في المطبخ & 17 \\
\hline 7 & .63 & 4.55 & تصطيخ شبكة الصـرف الصحي كبير، ويتحمل الضـغط العـالي في & 19 \\
\hline 8 & .70 & 4.51 & مصادر الكهرباء موزعة بشكل جيد وبعيدة عن مصادر المياه & 22 \\
\hline 9 & .76 & 4.41 & تتوفر تهوية جيدة للعاملين في المطبخ & 16 \\
\hline
\end{tabular}


Analyze Factors Affect on Five Stars Occupational Safety...

\begin{tabular}{|c|c|c|c|c|}
\hline 10 & .88 & 4.37 & وضع شبك على النو افذ لمنع دخول الحشرات & 18 \\
\hline 11 & 1.00 & 4.30 & الأطعة مطلي بمادة تمنع التقاط الأبخرة التي تشكل تلوثا يؤثر على & 21 \\
\hline 12 & .99 & 4.30 & أرضية المطبخ مبلطه ببلاط خشن يمنع الانز لاق & 24 \\
\hline
\end{tabular}

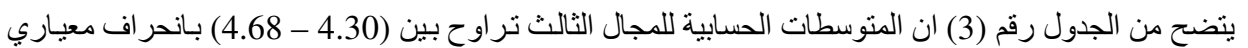

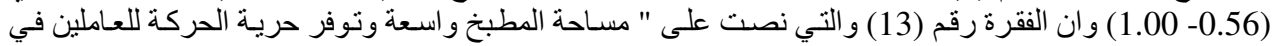

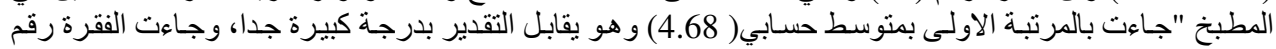

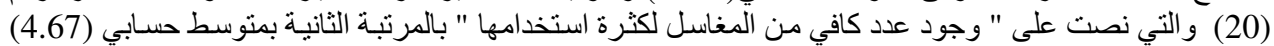

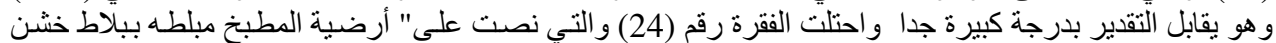
يمنع الانز لاق " بالمرتبة الأخيرة بمتوسط حسابي ( 4.30) وهو يقابل التقبير بدرجة كبيرة.

جدول رقم (4) المتوسطات الحسابية والانحرافات المعيارية لتقديرات افراد العينة لواقع سلامة العاملين في المطبخ مرتبة تنازليا حسب المتوسطات الحسابية

\begin{tabular}{|c|c|c|c|c|}
\hline الرتبة & 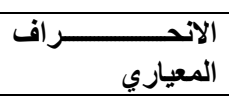 & الحستوسيـــ المبـ & الفقرات & الرقم \\
\hline 1 & .62 & 4.72 & هناك تعليمات باستعمال ألو اح التقطيع الخاصة باللحوم & 30 \\
\hline 2 & .53 & 4.70 & فوري إن وجليمت من الإدارة بإز الـة المـاء والدهون عن الأرض بشكل & 31 \\
\hline 3 & .57 & 4.70 & الرغوة ) مراة وجود طفايات حريق بعدة أنواع مثل ( البودرة ، السائل ، & 33 \\
\hline 4 & .55 & 4.68 & هنالك تعليمات بعدم فتح العلب باستخدام السكينة & 29 \\
\hline 5 & .58 & 4.68 & وجود صندوق للإسعافات الأولية للعاملين في المطبخ & 32 \\
\hline 6 & 67 & 4.67 & 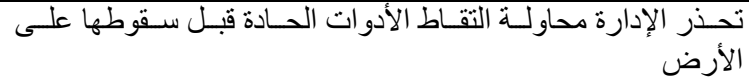 & 28 \\
\hline 7 & .67 & 4.63 & تحذر الإدارة من مسك السكاكين من الأماكن الحادة عند استعمالها. & 27 \\
\hline 8 & .53 & 4.60 & تمنع إدارة الفندق الركض داخل المطبخ & 25 \\
\hline 9 & 67 & 4.58 & 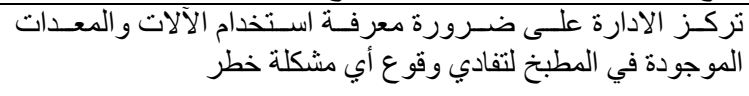 & 35 \\
\hline 10 & .73 & 4.58 & 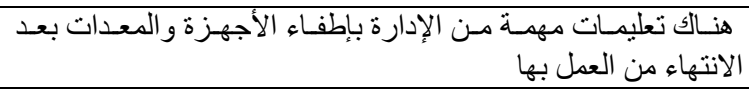 & 36 \\
\hline 11 & .66 & 4.56 & هالة حدوثهاك تو جات بضـرورة إنهاء مشـاكل العاملين داخل المطبخ في & 34 \\
\hline 12 & .66 & 4.49 & الأدوات و المعدات الثقيلة الموجودة في المطبخ تحفظ على رفوف & 26 \\
\hline
\end{tabular}

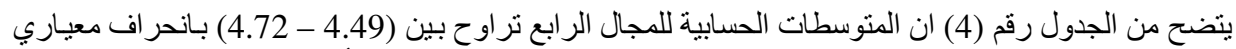

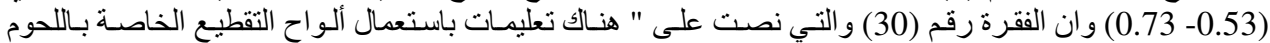

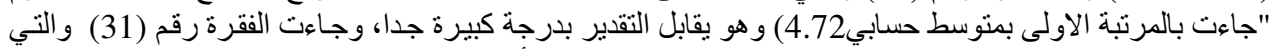

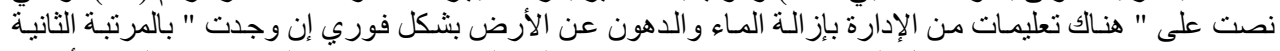

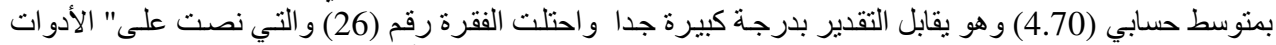

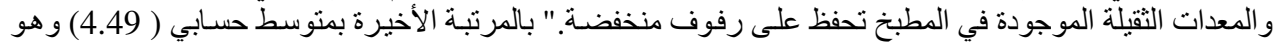

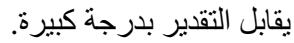




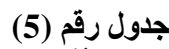

نتائج الأداة ككل

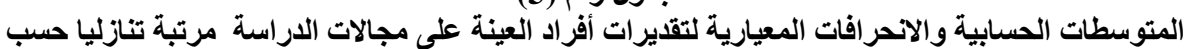

المتوسطات الحسابية

\begin{tabular}{|c|c|c|c|c|}
\hline الرتبة & الاتحراف المعياري & الحستوسيــــــــــ & المجالات & 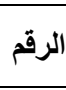 \\
\hline 1 & .37 & 4.63 & سلامة العاملين في المطبخ & 4 \\
\hline 2 & .49 & 4.54 & برنامج الأمن و السلامة المهنية & 1 \\
\hline 3 & .48 & 4.51 & تصميم المطبح & 3 \\
\hline 4 & .73 & 4.27 & قسم السلامة المهنية & 2 \\
\hline & .41 & 4.49 & & الكلي \\
\hline
\end{tabular}

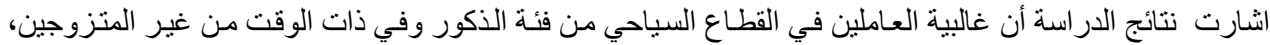

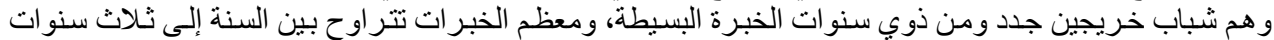

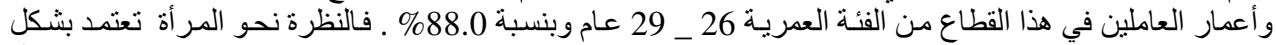

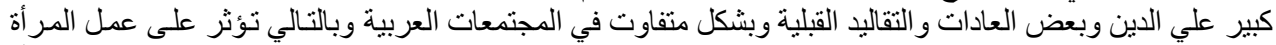

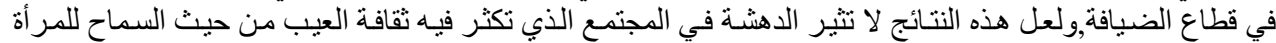

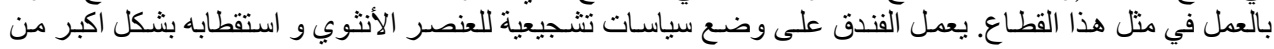

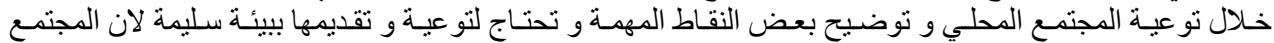

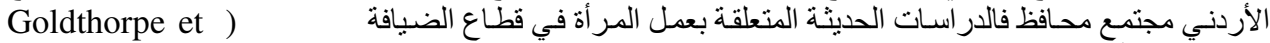
(al,1968 بدأت من خلال توجة المر اة للعمل بهذا القطاع دعم الاسرة ماديـا( طويل الامد في المجتمع الاردني للعمل في الفنادق.

أما فيما يخص العلاقة بين البيانات الديمو غر افية وبيئة العمل فقد أظهرت النتائج وجود علاقة ذات دلالة إحصائية بين

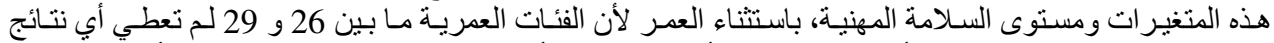

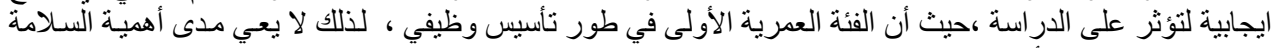

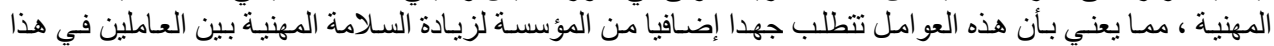

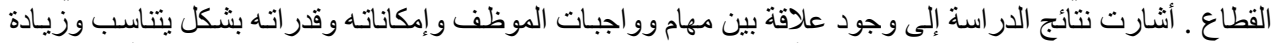

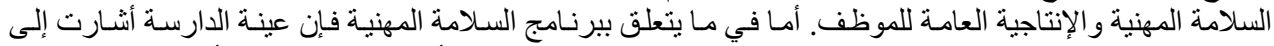

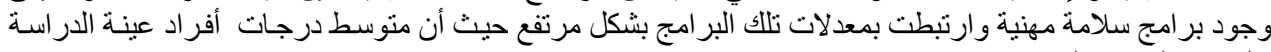

على هذا البعد قد بلغت 39.4 \%

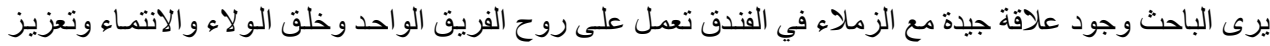

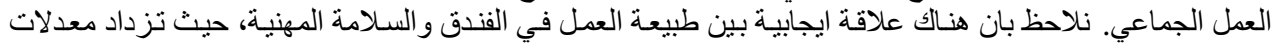

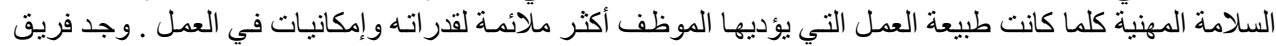

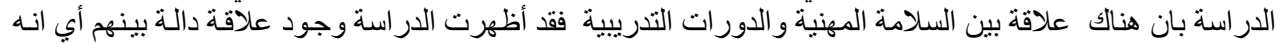

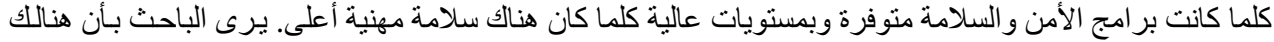

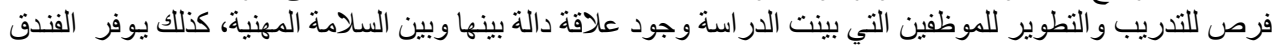

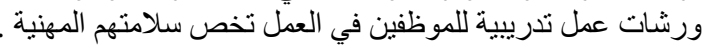

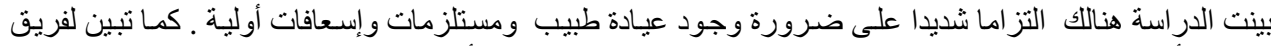

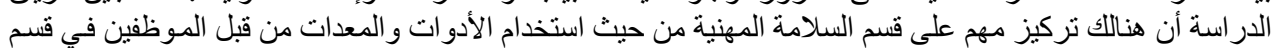

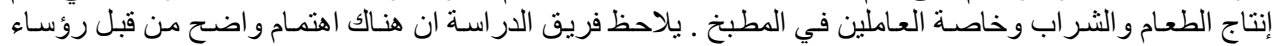

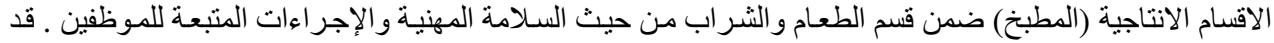

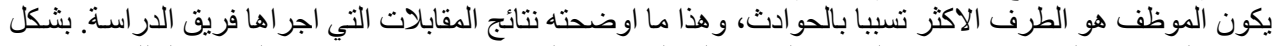

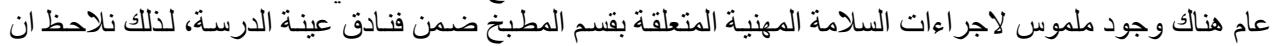

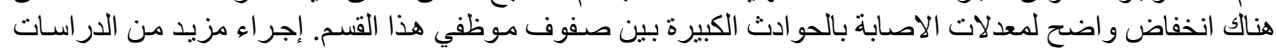

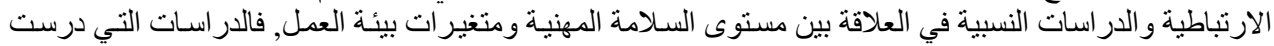




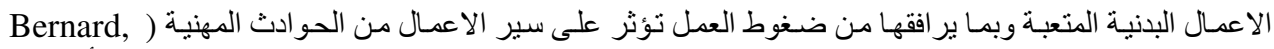

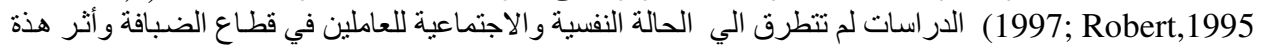

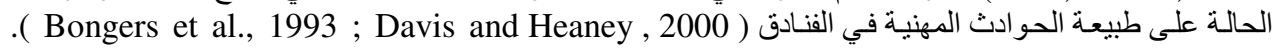

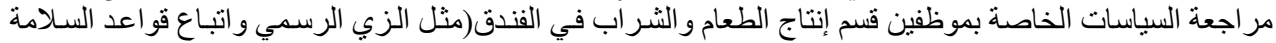

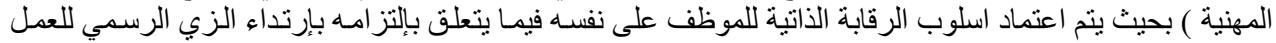
حرصا على سلامته . مانه

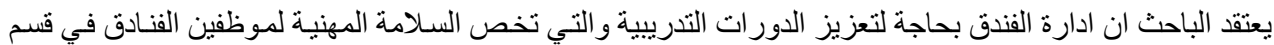

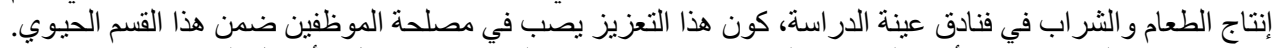

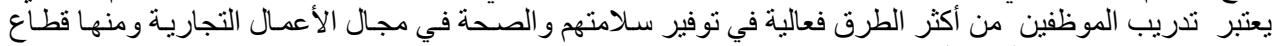

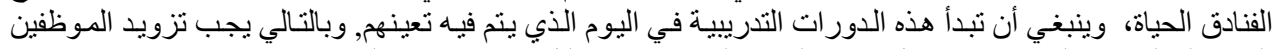

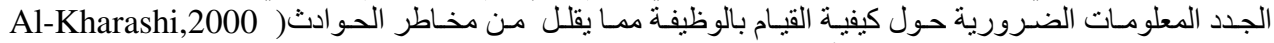
( Demir et al,2005;

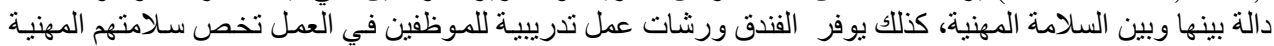

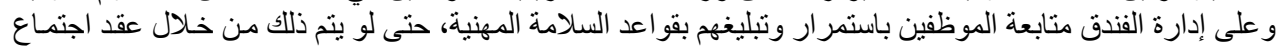

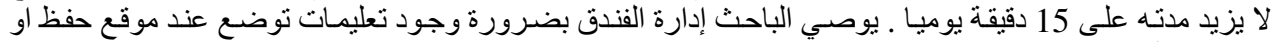

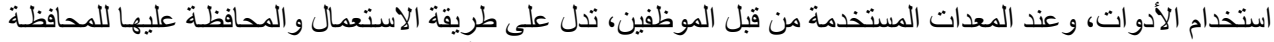

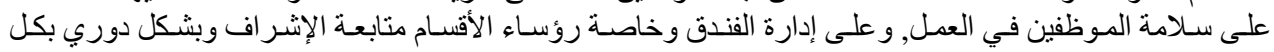

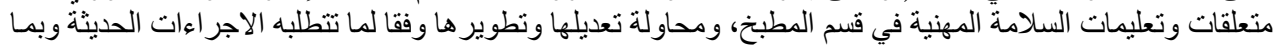
يتناسب و احتياجات الموظفين .

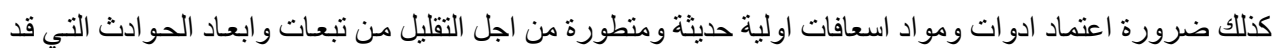

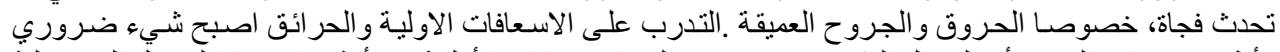

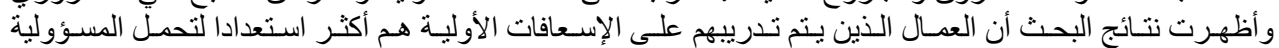

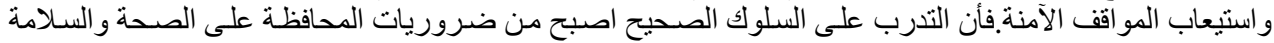

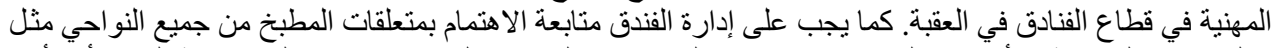

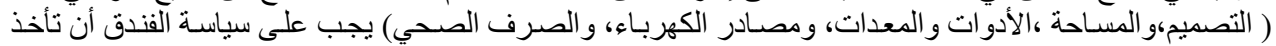

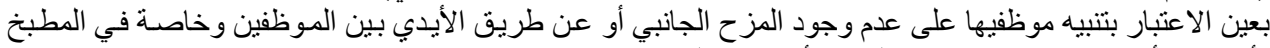

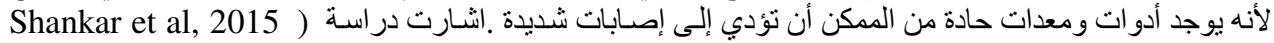

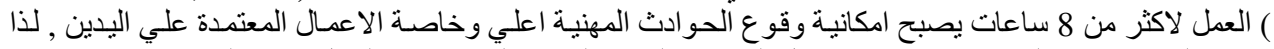

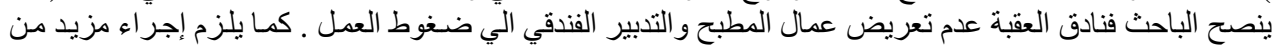

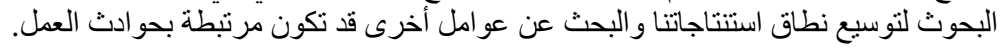

\section{References}

Abbas, Suhaila Mohammed (2003). "Human Resources Management", Dar Wael Publishing and Distribution, Jordan.

Abbey, James R. (1997). Hospitality Sales and Marketing, Educational Institute Of American Hotel and Lodging Association.

Abu Qahaf, Abdel Salam (1988). "Organization and Management of Tourism and Hotel Facilities", Modern Arab Office, Egypt.

Abu Saud, Bassam Fatin (1989). "An Analytical Study of the Reality of Occupational Safety in the Jordanian Industrial Companies", Unpublished a Master's Degree at the University of Jordan.

Abu Sheikha, Nader Ahmed (2000), Human Resource Management, Hashemite University, Jordan. 
AFL-CIO Working for America Institute (2002). U.S. Hotels and their Workers: Room for Improvement. Washington, DC: AFL-CIO Working for America Institute.

Al-Kharashi, Mazen and Abdel-Karim (2000). "Occupational Safety", Safa Publishing House, Jordan.

Al-Mari, Hamad Mohammed (1987). "Safety and Security in Institutions and Establishments", Al Falah Library, Kuwait.

Al-Sahawneh, Polus, (2005). "A Study on the Degree of Commitment of Professional Industrial Education Teachers to Security and Safety Stresses in Occupational Occupations", The University of Jordan.

Bernhardt A, Dresser L, Hatton E. (2003). The Coffee Pot Wars: Unions and Firm Restructuring in the Hotel Industry. In: Appelbaum E, Bernhardt A, Murnane RJ, editors. Low-wage America: How employers are reshaping opportunity in the workplace. New York: Russell Sage Foundation, p 33-76.

Bernard BP, editor.( 1997). Musculoskeletal disorders and workplace factors. Cincinnati, OH: U.S. Department of Health and Human Services, Public Health Service, Centers for Disease Control and Prevention, National Institute for Occupational Safety and Health. DHHS (NIOSH) Publication No. 97-141.

Bongers PM, de Winter CR, Kompier MAJ, Hildebrandt VH.(1993). Psychosocial factors at work and musculoskeletal disease. Scan JWork Environ Health 19:297-312.

Bureau of Labor Statistics. (2003). Survey of Occupational Injuries and Illnesses, Table I. Incidence Rates of Nonfatal Occupational Injuries and Illnesses by Industry and Selected Case Types, 2002: U.S. Department of Labor. Available at:

http://www.bls.gov/iif/oshwc/osh/os/ostb1244.pdf. Accessed: Feb. 3, 2016.

Dasinger LK, Krause N, Deegan LJ, Brand RJ, Rudolph L. (1999). Duration of Work Disability after Low Back Injury: A Comparison of Administrative and Self-Reported Outcomes. Am J Ind Med 35:619-631.

David, K.Hayes, Jack D.Ninemeier, (2007). Hotel Operations Management, By Pearson Education, Inc., New Jersey.

Davis KG, Heaney CA. (2000). The Relationship between Psychosocial Work Characteristics and Low Back Pain: Underlying Methodological Issues. Clin Biomech (Bristol Avon) 15:389-406.

Demir, C. Çolakoglu, Ü. Çolakoğlu, O. Çavus, ù. Aydin, ù. Good, T. Yenipınar, U. Çavus, Ö. H. Güzel, B. Kilınc, U. (2005). Accommodation Human Resource Management in Businesses: Principles and Practices. Nobel Yay.

Evanoff B, Abedin S, Grayson D, Dale AM, Wolf L, Bohr P. (2002). Is Disability Underreported Following Work Injury? J Occup Rehabil 12: 139-150. 
Goldthorpe, J., Lockwood, D., Bechhofer, F., and Platt, J. (1968). The Affluent Worker: Industrial Attitudes and Behavior. Cambridge, UK: Cambridge University Press.

Khalaf, Mohamed. (1992). "Occupational Health and Safety and its Impacts on Morale and Productivity, The University of Jordan.

Krause N, Rugulies R, Ragland DR, Syme SL. (2004). Physical Workload, Ergonomic Problems, and Incidence of Low Back Injury: A 7.5-Year Prospective Study of San Francisco Transit Operators. Am J Ind Med 46:570-585.

Krause N, Dasinger LK, Deegan LJ, Brand RJ, Rudolph L. (1999). Alternative Approaches for Measuring Duration of Work Disability after Low Back Injury based on Administrative Workers' Compensation Data. Am J Ind Med 35:604-618.

Jumaili, Qusay Qahtan Khalifa (2004). "Human Resources in Hotels", National Library, Jordan.

Mohammed A Abu Rumman, Omar AA Jawabreh, Khaled MK Alhyasat, Husam MJ Abu Hamour.(2014). The Impact of Work Environment on the Average of Job Turnover in Five-Star Hotels in Al-Aqaba City, Business Management and Strategy, Vol. 4, No. 2, doi:10.5296/bms.v4i2.4020.

Parker E, Krause N. (1999). Job Quality in the Hospitality Industry: Findings from the San Francisco Housekeeping Study Madison: Center on Wisconsin Strategy, University of Wisconsin-Madison. 23 pages.

Pransky G, Snyder T, Dembe A, Himmelstein J. (1999). Work-Related Disorders in the Workplace: A Case Study and Review of the Literature. Ergonomics 42:171-182.

Robert, H.Woods, CHRE (1995). Human Resources Management, By The Educational Institute Of The American Hotel And Motel Association.

Rosenman KD, Gardiner JC, Wang J, Biddle J, Hogan A, Reilly MJ, Roberts K, Welch E. (2000). Why Most Workers with Occupational Repetitive Trauma do not File for Workers' Compensation. J Occ Env Med 42:25-34.

Railey, M., Ladkin, A., and Szivas, E. (2002). Tourism Employment, Analysis and Planning. Clevedon, UK: Channel View Publications.

Saleh, Hammam and Talal Dawood (2003) ."Kitchen Management and Processing", Arab College, Jordan.

Sarhan, Nael , Musa Mahmoud (2002). "Principles of Hotel Management", Department of National Library, Jordan.

Scherzer T, Rugulies R, Krause N. (2005). Work Related Pain and Injury and Barriers to Workers' Compensation among Las Vegas Hotel Room Cleaners. Am J Public Health 95:483-488. 
Journal of Social Sciences (COES\&RJ-JSS), 6(4), pp. 802-815

Shankar Subramaniam and Shanmugam Murugesan (2015). Investigation of WorkRelated Musculoskeletal Disorders among Male Kitchen Workers in South India, International Journal of Occupational Safety and Ergonomics, 21:4, 524-531, DOI: 10.1080/10803548.2015.1096063

Tawfiq, Maher Abdul Aziz (2006). "Hotel Management Science", Applied Science University, Jordan.

Zidan, Hassan (1995). "Industrial Security", Ezzedine Printing and Publishing, Jordan. 